Communication

\title{
Preparation and Synergistic Effect of Chitosan/Sodium Phytate/MgO Nanoparticle Fire-Retardant Coatings on Wood Substrate through Layer-By-Layer Self-Assembly
}

\author{
Feiyue Zhao, Tingli Tang, Sijie Hou and Yanchun Fu * \\ College of Furnishings and Industrial Design, Nanjing Forestry University, Nanjing 210037, China; \\ zhaoofeiyue@126.com (F.Z.); tangtingli777@163.com (T.T.); 15951909903@163.com (S.H.) \\ * Correspondence: yanchunfu@njfu.edu.cn; Tel.: +86-25-8542-7793
}

Received: 8 August 2020; Accepted: 28 August 2020; Published: 31 August 2020

check for updates

\begin{abstract}
Fire-retardant chitosan/sodium phytate/ $\mathrm{MgO}$ nanoparticle $(\mathrm{CH} / \mathrm{SP} / \mathrm{nano}-\mathrm{MgO})$ coatings were loaded on a wood substrate via electrostatic layer-by-layer self-assembly and characterized by scanning electron microscopy and energy-dispersive spectrometry. The flammability and thermal degradation of the original wood and wood samples treated with chitosan, chitosan/sodium phytate, chitosan/sodium phytate/MgO nanoparticles were studied by limiting oxygen index (LOI), exposure combustion experiments and thermogravimetric analysis (TGA), respectively. The $\mathrm{CH} / \mathrm{SP} /$ nano- $\mathrm{MgO}$ coating served as an intumescent fire-retardant system that created a physical protection cover and exhibited the best fire retardant performance. The LOI value was $30.2 \%$ and required approximately 16-17 s to self-extinguish when exposed to air. The TGA curves also showed that char formation protected the wood from combustion.
\end{abstract}

Keywords: wood; surface modification; fire retardancy; chitosan; sodium phytate; $\mathrm{MgO}$ nanoparticles; layer-by-layer self-assembly

\section{Introduction}

Wood is widely used in furniture manufacturing, building decoration, and other fields, but its flammability poses a fire risk; therefore, to improve the fire resistance of wood, while retaining its original characteristics, fire retardants are typically applied [1-4]. For many years, composite inorganic fire retardants containing phosphorus, nitrogen, and boron were the main wood fire retardants [5-8]. During combustion, the decomposition of fire retardant produces a dehydrating agent that can directly dehydrate and carbonize wood to form a dense carbon layer that separates wood from the heat source and oxygen to terminate combustion.

Traditional intumescent fire-retardant coatings have low fire retardant efficiencies and poor weather resistance. Previous studies have shown that metal oxides/hydroxide can increase the formation of coke, water, and other low-molecular-weight compounds by reducing the formation of L-glucose and flammable volatiles [9-11]. This affects the thermal decomposition kinetics and pyrolysis behavior of fibers and produces a synergistic effect with intumescent fire retardants to improve their performance. Sain et al. studied the flammability of wood sawdust/rice husk filled polypropylene composites and flame effect of $\mathrm{MgO}$ on the composites through horizontal combustion and oxygen index tests. The results show that the presence of $\mathrm{MgO}$ can effectively reduce the flammability of natural fiber filled polypropylene composites (nearly 50\%) [12]. Guo's team prepared a fire-retardant $\mathrm{Mg}-\mathrm{Al} \mathrm{LDH}$ coating on wood surface with a two-step synthetic method, which significantly improveed the mechanical properties and flame retardancy of birch wood specimens. Compared with untreated 
wood, the storage modulus of the $\mathrm{Mg}-\mathrm{Al} \mathrm{LDH}$-coated wood was improved by up to $32 \%$, while the limiting oxygen index increased from $18.9 \%$ to $39.1 \%$. The heat release index measured by cone calorimetry was reduced by $40 \%$, and the smoke emission was reduced by $58 \%$ [13].

In addition to the reagents used, the performance of wood fire retardants largely depends on the treatment method. Jiang et al. studied the effects of fire retardant action of wood treated with fire retardants that were obtained from phosphorus acid, pentaerythritol, urea, and triethanolamine through copolycondensation. The results showed that adding the fire retardant decreases the thermal activation energy at a high degree of degradation, leading to the increase in LOI values [14]. Zhang et al. enhanced the fire-retardant performance of cellulose fibers by ion-exchange and grafting. Unfortunately, due to the low grafting rate, low ion-exchange efficiency, and complex grafting process, the fire retardant efficiency was not very high [15]. Blended wet spinning is a simple and direct method; however, the addition of fire retardants to fibers in a wet bath is mainly limited by the addition of fire retardants [16]. In recent years, our team has focused on polyelectrolyte/metal oxide nanoparticle coatings loaded on wood substrates through layer-by-layer self-assembly, which is easy to operate, does not require complex instruments, and has excellent protection performance [17-19].

In this paper, sodium phytate, chitosan, and magnesium oxide nanoparticles were used to prepare fire-retardant wood by electrostatic layer-by-layer self-assembly. The amino groups in the molecular chains of chitosan can be protonated under acidic conditions, allowing chitosan to be used as a polycation with a high nitrogen content $[20,21]$. Sodium phytate is a natural polyanion with good hydrophilicity, and its high phosphorus content makes it suitable for use as a fire retardant [22,23]. The combination of phosphorus and nitrogen compounds improves the fire retardancy of wood. $\mathrm{MgO}$ nanoparticles have a uniform filling effect that can prevent the heat transfer of fiber and block combustion channels, providing a long-lasting fire retardant effect $[16,24]$.

\section{Materials and Methods}

\subsection{Experimental Materials}

Balsa wood (O. pyramidale) was purchased from Dongguan Senyu Wood Industry Co., Ltd. (Dongguan, China). Magnesium oxide nanoparticles (particle size: $50 \mathrm{~nm}$ ) and chitosan (low viscosity: $<200 \mathrm{MPa} \cdot \mathrm{s}$ ) were supplied by Shanghai Machlin Biochemical Co., Ltd. (Shanghai, China). Hydrochloric acid (36.5\%-38.0\%) was purchased from Sigma-Aldrich (Shanghai, China). Sodium phytate $(99.0 \%)$ was purchased from Hefei Bosf Biotechnology Co., Ltd. (Hefei, China). The water used in the experiment was distilled water purified in-house.

\subsection{Fabrication of Fire Retardant Coatings on Wood Surface}

Chitosan (1 g), sodium phytate (1 g), and MgO nanoparticle powder $(1 \mathrm{~g})$ were separately dissolved in three beakers containing $100 \mathrm{~mL}$ distilled water and stirred continuously on a magnetic stirrer. Dilute hydrochloric acid was added until the $\mathrm{pH}$ of each solution was 2-3. At this point, chitosan solution and $\mathrm{MgO}$ nanoparticle solution showed positive charge, and sodium phytate solution showed negative charge [25-27].

Wood samples were cut into several small samples that were washed three times with distilled water and dired in an oven at $60^{\circ} \mathrm{C}$ for $60 \mathrm{~min}$. The pre-treated wood specimens were immersed in chitosan solution for $90 \mathrm{~min}$ and then rinsed with distilled water until there was no residue on the surface, and dired in an oven at $60^{\circ} \mathrm{C}$ for $60 \mathrm{~min}$. Afterward, the treated samples were immersed in sodium phytate solution for $90 \mathrm{~min}$, washed with distilled water until there was no residue on the surface, and dired in an oven at $60^{\circ} \mathrm{C}$ for $60 \mathrm{~min}$. In the last step, the wood samples were immersed in an aqueous magnesium oxide nanoparticle solution for $90 \mathrm{~min}$, washed with distilled water until there was no residue on the surface, and dried in an oven at $60^{\circ} \mathrm{C}$ for $60 \mathrm{~min}$. For easier presentation, the wood treated with chitosan was labeled as $\mathrm{CH}$ wood, the wood treated with chitosan and sodium phytate sequentially was named CH/SP wood, the wood treated with chitosan, sodium phytate, 
and $\mathrm{MgO}$ nanoparticles was named $\mathrm{CH} / \mathrm{SP} /$ nano- $\mathrm{MgO}$ wood. A layer of sodium phytate and a layer of $\mathrm{MgO}$ nanoparticles were considered to consistute an assembly cycle. In this study, multiple assembly cycles were used for each specimen (Figure 1) to ensure uniform coverage. Assembly structure and invariants of as-prepared samples as listed in Table 1.

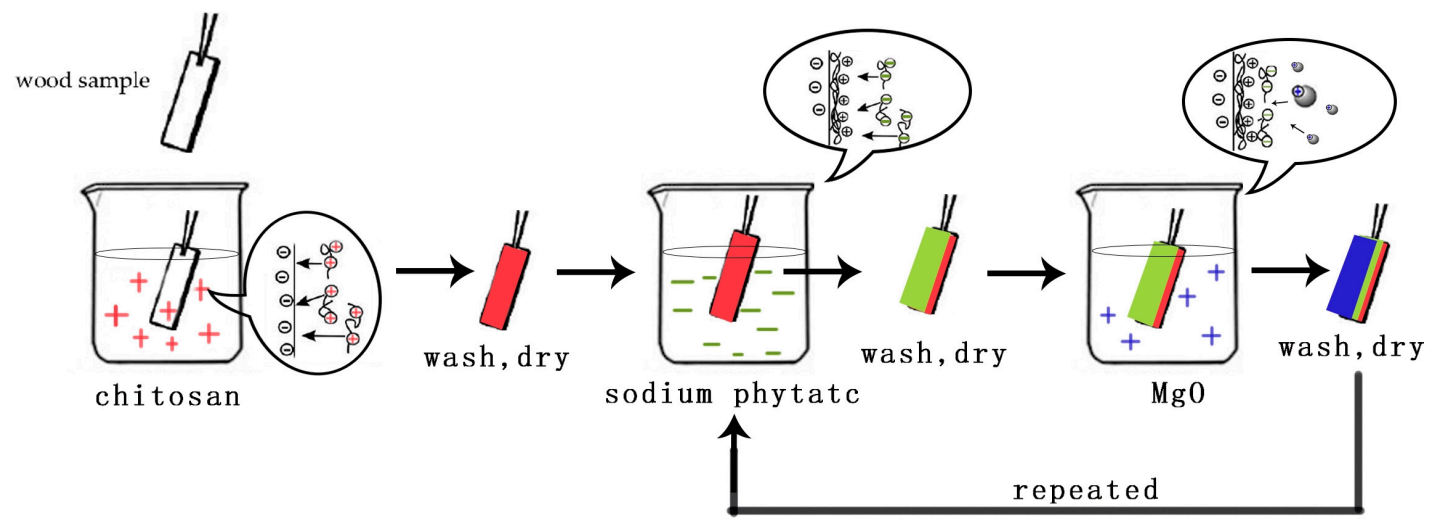

Figure 1. Scheme of fabricating chitosan/sodium phytate/MgO nanoparticle fire-retardant coatings on wood substrate through layer-by-layer self-assembly.

Table 1. Assembly structure and invariants of coated samples.

\begin{tabular}{cc}
\hline Sample Name & Assembled Structure \\
\hline $\mathrm{CH}$ & Wood $/ \mathrm{CH} / \mathrm{CH} / \ldots$ \\
$\mathrm{CH} / \mathrm{SP}$ & Wood $/ \mathrm{CH} / \mathrm{SP} / \mathrm{CH} / \mathrm{SP} / \ldots$ \\
$\mathrm{CH} / \mathrm{SP} /$ nano-MgO & Wood $/ \mathrm{CH} / \mathrm{SP} / \mathrm{MgO} / \mathrm{SP} / \mathrm{MgO} / \ldots$ \\
\hline &
\end{tabular}

Immersion time: $90 \mathrm{~min}$; Assembly cycle: 5; Mass volume concentration (chitosan, sodium phytate, nano-MgO): $1 \%$.

\subsection{Characterization}

The surface micromorphology of the as-prepared wood samples wereobserved by scanning electron microscopy (SEM, Quanta 400 FEG, FEI Inc., Eindhoven, The Netherlands). Each sample was pre-dried for $60 \mathrm{~min}$ andspayed with a 5-10 $\mathrm{nm}$ Au layer before SEM imaging. In addition, the surface chemical compositions of wood specimens was analyzed by SEM equipped with electron microscope.

\subsection{Thermogravimetric Analysis}

Thermogravimetric analysis (TG209, NETZSCH, Selb, Germany) was carried out to measure the thermal stability of wood samples before and after treatment. Test condition: the thickness of the sample was $0.5 \mathrm{~mm}$, the heating rate was $10^{\circ} / \mathrm{min}$, the temperature range was $30-800{ }^{\circ} \mathrm{C}$, and nitrogen protection was adopted during the test.

\subsection{Limiting Oxygen Index Test}

The limiting oxygen index (LOI) of the samples was measured by an oxygen index tester (PX-01-005, Phoenix, Suzhou, China). After the instrument was set to the standard conditions, a sample with a size of $120 \mathrm{~mm} \times 10 \mathrm{~mm} \times 4 \mathrm{~mm}$ was placed vertically in the oxygen and an oxygen mixture adjusted to a specific proportion. When the airflow stabilized, the wood sample was ignited at the top of the specimen. During combustion, the oxygen concentration in the experimental environment gradually decreased, and the combustion will be limited and terminated. Finally, the minimum oxygen concentration required for the wood sample to maintain stable combustion for $3 \mathrm{~min}$ or at a position of $5 \mathrm{~cm}$ was recorded and determined as its oxygen index, expressed as oxygen volume percentage. 


\subsection{Exposure Combustion Test}

Exposure combustion tests were conducted by directly igniting wood samples. The specific operation was to place a wood sample $(120 \mathrm{~mm} \times 10 \mathrm{~mm} \times 4 \mathrm{~mm})$ in the environment and ignite it. Then, its combustion state and the total time from ignition to complete extinction were recorded, and the fire-retardant trend was observed to judge the fire-retardant performance of wood. To reduce the experimental error, the experiment was repeated five times for each group of samples. After observing and comparing the combustion of five samples, we selected representative samples for further investigation.

\section{Results}

\subsection{Surface Morphologies Analysis}

The wood surface morphology was investigated by SEM (Figure 2), which showed that the fiber structure of the wood sample treated by film mulching was complete and undamaged. Representative SEM images of raw wood, $\mathrm{CH}, \mathrm{CH} / \mathrm{SP}$, and $\mathrm{CH} / \mathrm{SP} /$ nano-MgO wood samples are shown in Figure 2a-d, which show holes on the surface of the original wood, as indicated by the red arrow (Figure 2a). In contrast, the holes on the $\mathrm{CH}$ wood surface after film mulching are filled and covered with a thin coating layer, as indicated by the red arrow (Figure 2b). There are almost no pits on the CH/SP wood surface covered with a smooth coating layer (Figure 2c). In Figure 2d, the surface is densely covered with a thick layer of evenly-distributed nanoparticles. The composition of the multilayer film was verified by EDS spectra. In addition to $C$ (Figure 2e) due to the chemical constituents of wood ( $\mathrm{N}$ element is negligible), new signals from N (Figure 2f), P (Figure 2g), and $\mathrm{Mg}$ (Figure 2h) were observed. This further demonstrates that $\mathrm{CH} / \mathrm{SP} /$ nano-MgO coatings were successfully immobilized on the wood substrate and that the hierarchical thin films were composed of chitosan, sodium phytate and $\mathrm{MgO}$ nanoparticles.


Figure 2. Cont. 

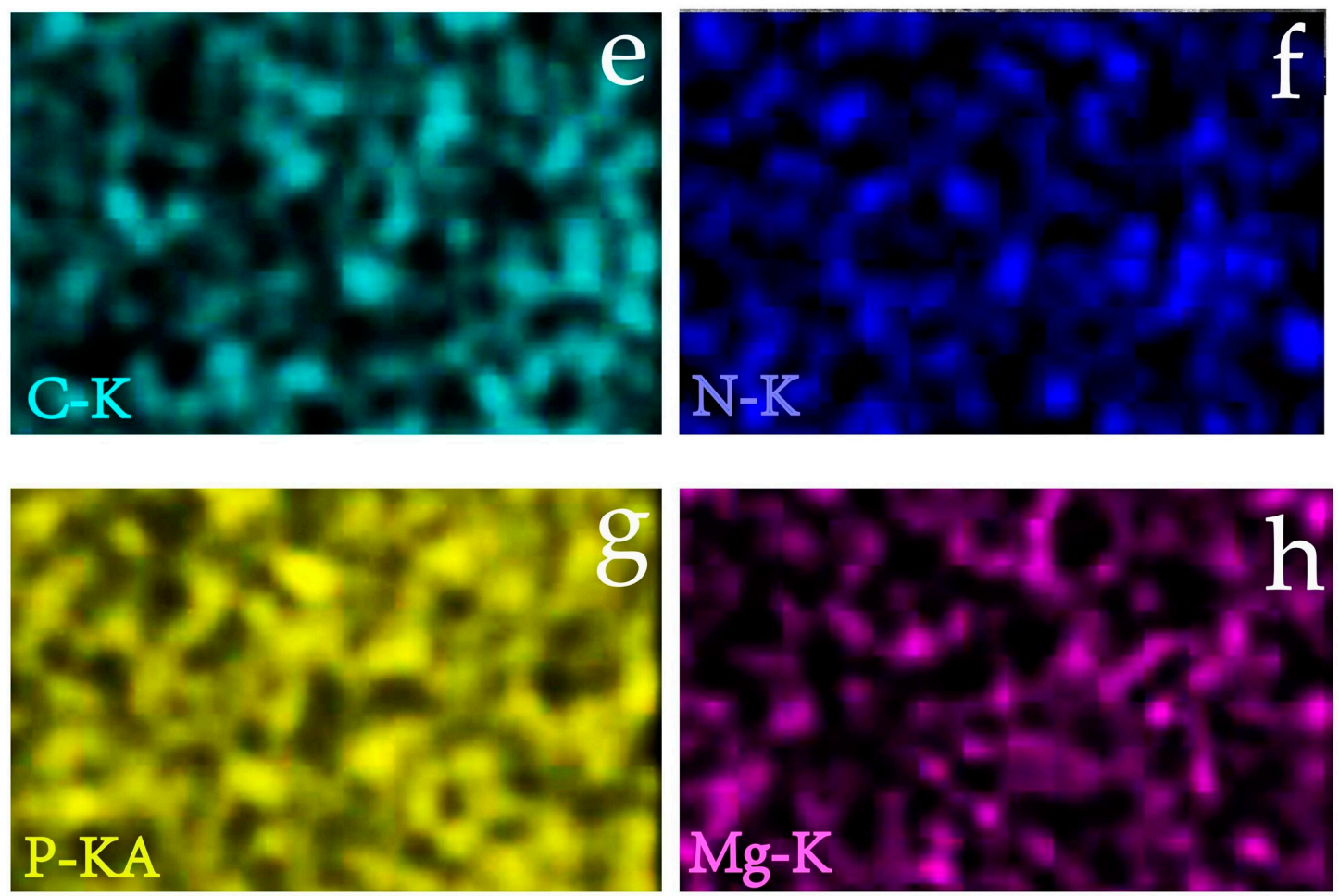

Figure 2. SEM images of (a) untreated wood; (b) $\mathrm{CH}$ wood; (c) $\mathrm{CH} / \mathrm{SP}$ wood and (d) $\mathrm{CH} / \mathrm{SP} /$ nano-MgO wood. EDS analysis of $\mathrm{CH} / \mathrm{SP} /$ nano-MgO coatings interface: (e) element $\mathrm{C}$; (f) element $\mathrm{N}$; (g) element $\mathrm{P}$; (h) element $\mathrm{Mg}$.

\subsection{Thermal Stability Analysis}

TGA was carried out to analyze the synergistic effects of chitosan, sodium phytate, and $\mathrm{MgO}$ nanoparticles on the wood fire retardancy (Figure 3). When the temperature was lower than $250{ }^{\circ} \mathrm{C}$, the wood was mainly dried and pre-decomposed. The results showed that the weight loss rate of the $\mathrm{CH} / \mathrm{SP} /$ nano-MgO wood and $\mathrm{CH} / \mathrm{SP}$ wood samples were significantly higher than that of the $\mathrm{CH}$ wood and original wood samples. This may have occurred because sodium phytate in the $\mathrm{CH} / \mathrm{SP}$ and $\mathrm{CH} / \mathrm{SP} /$ nano-MgO multilayers produced phosphoric acid and polyphosphate during combustion, which catalyzed the thermal degradation of wood; thus, it promoted the carbonization and dehydration of wood and significantly reduced its weight. After this stage, the thermal decomposition of the $\mathrm{CH} / \mathrm{SP}$ and $\mathrm{CH} / \mathrm{SP} /$ nano-MgO wood samples entered an intense pyrolysis process of cellulose and residual hemicellulose. The thermal degradation rate of untreated and $\mathrm{CH}$-coated wood decreased, which manifested as a slow reduction in the char residual amount. The lower thermal stability might be attributed to the presence of the sodium phytate and $\mathrm{MgO}$ coatings. Sodium phytate, which contained phosphorus, might accelerate the thermal degradation of cellulose. In the third stage-i.e., $450-800{ }^{\circ} \mathrm{C}$, the pyrolysis was nearly complete, and the residual weight of all samples was stable.

A comparison shows that the residual mass of the treated specimens was higher than that of the untreated samples in the order: $\mathrm{CH} / \mathrm{SP} /$ nano- $\mathrm{MgO}>\mathrm{CH} / \mathrm{SP}>\mathrm{CH}>$ original wood. Introducing chitosan, sodium phytate, and $\mathrm{MgO}$ nanoparticles can change the thermal decomposition of wood and reduce its burning damage. The appearance of a higher residual char amount protected the wood from flame; as a result, mass/heat transfer was retarded, and the fire retardancy of modified wood was improved. 


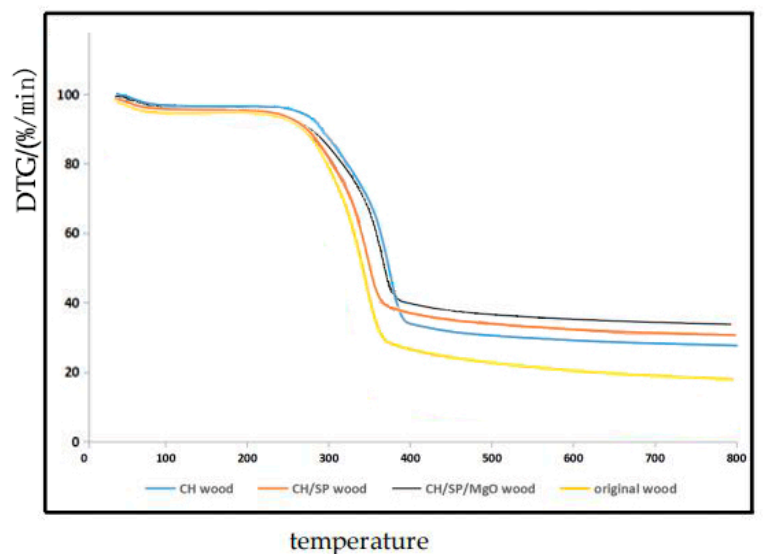

(a)

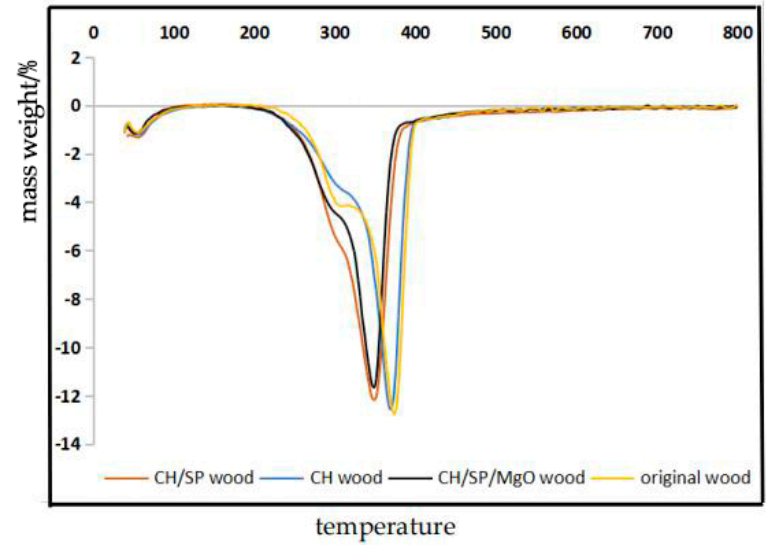

(b)

Figure 3. TG (a) and DTG (b) curves of the original, $\mathrm{CH}, \mathrm{CH} / \mathrm{SP}$ and $\mathrm{CH} / \mathrm{SP} /$ nano-MgO wood samples.

\subsection{Fire Resistance Test}

The fire resistance of all specimens was evaluated by limiting oxygen index (LOI) tests. As is well-known, wood is a typical combustible material. According to Figure 4, the original wood had a low LOI (24.1\%). The LOI value of the $\mathrm{CH}$ wood increased to $26.1 \%$. Although it has a certain fire retardant trend, the $\mathrm{CH}$ wood is still a combustible material. The further adhesion of sodium phytate makes the trend of wood fire retardant more obvious. The LOI value of the CH/SP wood is 28.5, which is basically a kind of refractory material. After the introduction of $\mathrm{MgO}$ nanoparticles, the LOI value of $\mathrm{CH} / \mathrm{SP} /$ nano- $\mathrm{MgO}$ reached $30.2 \%$. These results suggest that chitosan, sodium phytate, and $\mathrm{MgO}$ nanoparticles played a synergistic role in improving the fire retardancy of the wood.

For a more intuitive observation, the fire retardancy of the original wood, $\mathrm{CH}, \mathrm{CH} / \mathrm{SP}$, and $\mathrm{CH} / \mathrm{SP} /$ nano-MgO wood samples was observed by direct exposure to an alcohol lamp flame. The progress of the initial fire spreading and self-extinguishing time were recorded for all four samples (Figure 5). The results show that once the original wood was ignited, it rapidly and violently burned, and the fire showed no sign of self-extinguishing (Figure 5a1). Finally, the whole wood sample was combusted (Figure 5a2). In contrast, the other three groups of treated wood samples were spotted before being automatically extinguished. The $\mathrm{CH}$ wood and $\mathrm{CH} / \mathrm{SP}$ wood kept burning in the initial fire spreading (6-7 s), but the fire is obviously smaller than the original wood (Figure 5b1, 5c1). CH wood was self-extinguished after 44-45 s, while CH/SP wood after 22-23 s showed a better fire retardant effect. As can be seen from Figure $5 \mathrm{~d} 1$, the $\mathrm{CH} / \mathrm{SP} /$ nano-MgO wood seemed to have been extinguished after burning for 6-7 s, and the fire was very small. In less than $17 \mathrm{~s}$, the fire was extinguished (Figure 5d2). This result is further verified that phosphoric acid and metaphosphoric acid produced by the thermal 
degradation of sodium phytate were dehydrated to form charcoal, which formed a protective carbon layer after combustion, which prevented continuous combustion. Meanwhile, magnesium oxide adhered to the surface of sodium phytate layer and further prevented combustion.

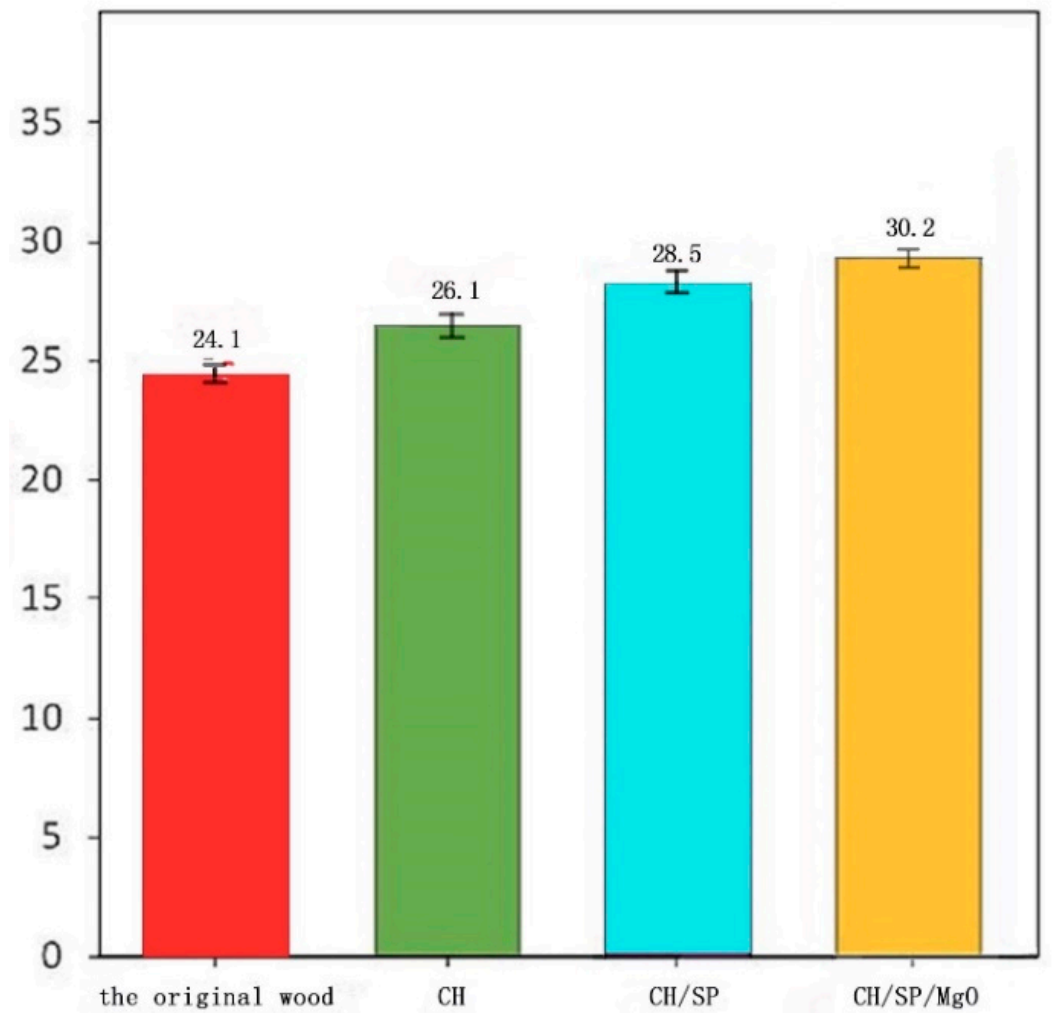

Figure 4. Limiting oxygen index (LOI) of the original wood (red), $\mathrm{CH}$ wood (green), $\mathrm{CH} / \mathrm{SP}$ wood (blue), $\mathrm{CH} / \mathrm{SP} /$ nano-MgO wood (yellow).
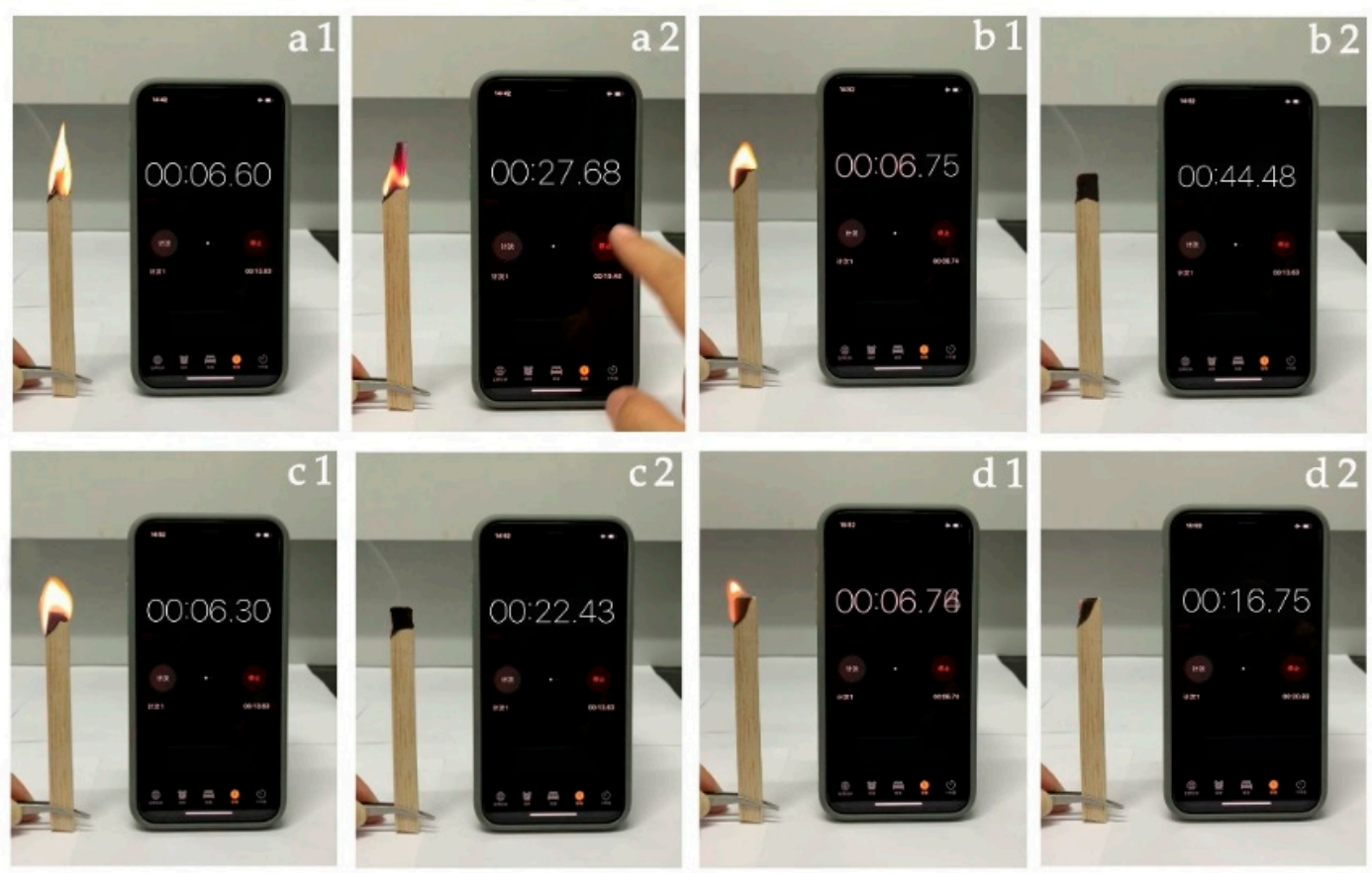

Figure 5. Exposure combustion tendency of $(\mathbf{a} 1, \mathbf{a} 2)$ original wood; $(\mathbf{b} 1, \mathbf{b} 2) \mathrm{CH}$ wood; $(\mathbf{c} 1, \mathbf{c} 2) \mathrm{CH} / \mathrm{SP}$ wood and (d1,d2) CH/SP/nano-MgO wood. 


\section{Conclusions}

In this study, wood substrates were coated with multilayered composite films of chitosan, sodium phytate, and MgO nanoparticles via layer-by-layer self-assembly, which was verified by EDS spectra. The SEM images showed that the wood surface was densely and evenly covered by a thick layer of evenly-distributed nanoparticles. The combustion performance and fire-retardant mechanism of the $\mathrm{CH}, \mathrm{CH} / \mathrm{SP}$, and $\mathrm{CH} / \mathrm{SP} /$ nano-MgO coated wood specimens were studied and compared with unmodified wood. The TGA, LOI, and exposure combustion results supported the beneficial effect of the three coatings on the fire-retardant properties of the wood. The nitrogen in protonated chitosan and the phosphorus in sodium phytate constituted a nitrogen-phosphorus fire retardant system. In the process of thermal degradation, the generated phosphoric acid and metaphosphoric acid dehydrated into charcoal, which leaded to the rapid formation of a carbonaceous protective layer soon after combustion initiation. During combustion, $\mathrm{MgO}$ nanoparticles in the wood also formed a layer that protected the material from the oxygen penetration and the spread of flammable gases. This indicated that chitosan, sodium phytate, and $\mathrm{MgO}$ nanoparticles synergistically improved the fire retardancy of wood.

Author Contributions: Conceptualization, methodology, Y.F.; software, validation, formal analysis, investigation, resources, data curation, F.Z., T.T., and S.H.; writing—original draft preparation, F.Z.; writing — review and editing, Y.F. All authors have read and agreed to the published version of the manuscript.

Funding: This research was funded by Youth Science and Technology Innovation Fund of Nanjing Forestry University, grant number CX2016016.

Conflicts of Interest: The authors declare no conflict of interest.

\section{References}

1. Gao, M.; Sun, C.; Wang, C. Thermal Degradation of Wood Treated with Flame Retardants. J. Therm. Anal. Calorim. 2006, 85, 765-769. [CrossRef]

2. Son, Y.S. A Study on Flame Retardant Treatment of National Cultural Properties of Wood Structure. Fire Sci. Eng. $1988,2,31-41$.

3. Kin, I.B.; Hyun, S.H. A Study on the Flame Retardant Performance and Toxicity of the Painting Wood Painted with Flame Retardant Solution. Fire Sci. Eng. 2009, 23, 66-71.

4. Merighi, S.; Mazzocchetti, L.; Benelli, T.; Maccaferri, E.; Giorgini, L. A new wood surface flame-retardant based on poly-m-aramid electrospun nanofibers. Polym. Eng. Sci. 2019, 59, 2541-2549. [CrossRef]

5. Phromsaen, A.; Prinya, C.; Hiziroglu, S.; Kasemsiri, P. Thermal degradation and fire retrandancy of wood impregnated with nitrogen phosphorus flame retardant. Adv. Mater. Res. 2014, 931-932, 152-156. [CrossRef]

6. Salman, S.; Pétrissans, A.; Thévenon, M.F.; Dumarçay, S.; Perrin, D.; Pollier, B.; Pollier, D.; Gérardin, P. Development of new wood treatments combining boron impregnation and thermo modification: Effect of additives on boron leachability. Eur. J. Wood Wood Prod. 2015, 72, 335-365. [CrossRef]

7. Guo, C.; Wang, S.; Wang, Q. Synergistic effect of treatment with disodium octaborate tetrahydrateand guanyl urea phosphate on flammability of pine wood. Eur. J. Wood Wood Prod. 2018, 76, 213-220. [CrossRef]

8. Yan, L.; Xu, Z.S.; Liu, D.L. Synthesis and application of novel magnesium phosphate ester flame retardants for transparent intumescent fire retardant coatings applied on wood substrates. Prog. Org. Coatins 2019, 129, 327-337. [CrossRef]

9. Lewin, M.; Endo, M. Catalysis of intumescent flame retardancy of polypropylene by metallic compounds. Polym. Adv. Technol. 2010, 14, 3-11. [CrossRef]

10. Wu, N.; Yang, R. Effects of metal oxides on intumescent flame-retardant polypropylene. Polym. Adv. Technol. 2011, 22, 495-501. [CrossRef]

11. Gao, W.; Yu, Y.; Chen, T.T.; Zhang, Q.W.; Chen, Z.W.; Chen, Z.Q.; Jiang, J.C. Enhanced flame retardancy of unsaturated polyester resin composites containing ammonium polyphosphate and metal oxides. J. Appl. Polym. Ence 2020, 137, 49148. [CrossRef]

12. Sain, M.; Park, S.H.; Suhara, F.; Law, S. Flame retardant and mechanical properties of natural fibre-PP composites containing magnesium hydroxide. Polym. Degrad. Stab. 2004, 83, 363-367. [CrossRef] 
13. Guo, B.T.; Liu, Y.Z.; Zhang, Q.; Wang, F.Q.; Wang, Q.W.; Liu, Y.X.; Li, J.; Yu, H.P. Efficient Flame-Retardant and Smoke-Suppression Properties of Mg-Al-Layered Double-Hydroxide Nanostructures on Wood Substrate. ACS Appl. Mater. Interfaces 2017, 9, 23039-23047. [CrossRef]

14. Zhang, J.; Yuan, S.F.; Wang, K.H.; Li, Q. Study on the Effects of Microwave Pretreatment on the Fire Retardant Permeability of Fast-Growing Wood. Appl. Mech. Mater. 2013, 2746, 1334-1338. [CrossRef]

15. Zhang, K.K.; Zong, L.; Tan, Y.Q.; Ji, Q.; Yun, W.C.; Shi, R.; Xian, Y.Z. Improve the flame retardancy of cellulose fibers by grafting zinc ion. Carbohydr. Polym. 2016, 136, 121-127. [CrossRef] [PubMed]

16. Li, X.M.; Zhang, K.K.; Shi, R.; Ma, X.M.; Tan, L.W.; Ji, Q.; Xian, Y.Z. Enhanced flame-retardant properties of cellulose fibers by incorporation of acid-resistant magnesium-oxide microcapsules. Carbohydr. Polym. 2017, 176, 246-256. [CrossRef]

17. Rao, X.; Liu, Y.; Fu, Y.; Liu, Y.; Yu, H. Formation and properties of polyelectrolytes/TiO2 composite coating on wood surfaces through layer-by-layer assembly method. Holzforschung 2016, 70, 361-367. [CrossRef]

18. Tang, T.L.; Fu, Y.C. Formation of Chitosan/Sodium Phytate/Nano-Fe ${ }_{3} \mathrm{O}_{4}$ Magnetic Coatings on Wood Surfaces via Layer-by-Layer Self-Assembly. Coatings 2020, 10, 51. [CrossRef]

19. Zhou, L.; Fu, Y.C. Flame-Retardant Wood Composites Based on Immobilizing with Chitosan/Sodium Phytate/Nano- $\mathrm{TiO}_{2}-\mathrm{ZnO}$ Coatings via Layer-by-Layer Self-Assembly. Coatings 2020, 10, 296. [CrossRef]

20. Rinaudo, M. Chitin and chitosan: Properties and applications. Prog. Polym. Sci. 2006, 31, 603-632. [CrossRef]

21. Tian, M.; Hu, X.; Qu, L.; Du, M.; Zhu, S.; Sun, Y.; Han, G. Ultraviolet protection cotton fabric achieved via layer-by-layer self-assembly of graphene oxide and chitosan. Appl. Surf. Sci. 2016, 377, 141-148. [CrossRef]

22. Liu, X.; Li, W.; Wang, W.; Song, L.; Fan, W.; Gao, X.; Xiong, C. Synthesis and characterization of pH-responsive mesoporous chitosan microspheres loaded with sodium phytate for smart water-based coatings. Mater. Corros. 2018, 69, 736-748. [CrossRef]

23. Liu, Y.; Wang, Q.Q.; Jiang, Z.M.; Zhang, C.J.; Li, Z.F.; Chen, H.Q.; Zhu, P. Effect of chitosan on the fire retardancy and thermal degradation properties of coated cotton fabrics with sodium phytate and APTES by LBL assembly. J. Anal. Appl. Pyrolysis 2018, 135, 289-298. [CrossRef]

24. Dhineshbabu, N.R.; Manivasakan, P.; Karthik, A.; Rajendran, V. Hydrophobicity, flame retardancy and antibacterial properties of cotton fabrics functionalised with $\mathrm{MgO} /$ methyl silicate nanocomposites. RSC Adv. 2014, 4, 32161-32173. [CrossRef]

25. Gariépy, E.R.; Leroux, J.C. Chitosan: A Natural Polycation with Multiple Applications. ACS Symp. Ser. 2006, 934, 243-259.

26. Yang, J.; Lu, H.; Li, M.; Liu, J.; Zhang, S.L.; Xiong, L.; Sun, Q.J. Development of chitosan-sodium phytate nanoparticles as a potent antibacterial agent. Carbohydr. Polym. 2017, 178, 311-321. [CrossRef]

27. Meng, X.; Liu, Z.M.; Deng, C.; Zhu, M.F.; Wang, D.Y.; Li, K.; Deng, Y.; Jiang, M.M. Microporous Nano-MgO/Diatomite Ceramic Membrane with High Positive Surface Charge for Tetracycline Removal. J. Hazard. Mater. 2016, 320, 495-503. [CrossRef]

(C) 2020 by the authors. Licensee MDPI, Basel, Switzerland. This article is an open access article distributed under the terms and conditions of the Creative Commons Attribution (CC BY) license (http://creativecommons.org/licenses/by/4.0/). 